\title{
Antroposen Çağı'nda Kentsellik, Sürdürülebilirlik ve Dirençlilik
}

\author{
Erkan POLAT $^{1}$, Sümeyye KAHRAMAN ${ }^{2}$
}

\section{Öz}

Artık değişen bir dünyada, kentsel ölçekli sürdürülebilirlik ve dirençlilik kavramlarını toplu olarak yeniden gözden geçirme zamanı geldi de geçiyor bile. Politik tartışmalarda sürdürülebilirliğin sürdürülmesi, aşırı karmaşıklık, radikal belirsizlikler ve benzeri görülmemiş bir değişim/dönüşüm ile karakterize edilen bir dünya yaratan Antroposen gerçeği görmezden gelme noktasının çok ötesine geçmiş durumda. Böyle bir dünyada sadece "sürdürülebilirlik ve dirençlilik" hedefi olarak bile olsa, bu kavramları tanımlamanın bile mümkün olmadığı gerçeği ile yüzleşmemiz şart görünüyor.

Farklı uzmanlık kürelerinde, farklı yorum ve tanımlara sahip iki soyut ve karmaşık kavram olan dirençlilik ve sürdürülebilir gelişme/kalkınma kavramları bir araya geldiğinde yeterince karmaşıkken, kapsama alanına kentsellik ve insanın baskınlığı/egemenliği anlamında Antroposen Çağı girdiğinde daha da kaotik bir durum ortaya çıkmaktadır. Antroposen, yalnızca antropojenik bir değişim dönemi değildir, dünyamız ve yaşadığımız gezegen hakkında yeniden düşünmemiz gerektiğini anlatan bir kavramdır ve gelişim/dönüşüm için derin etkileri vardır.

Kentsel ve bölgesel ölçekte, dirençlilik tanımlayıcı bir kavram olarak bir kentsel sistemin dinamik özellikleri ve uyum sağlama kapasitesi hakkında fikir verirken, sürdürülebilirlik normatif bir kavram olarak, nesiller arası ve nesiller-ötesi (trans-generational) adaletin temel fikirlerini ortaya koyar. Bu çalışmada dirençlilik, kentsellik ve sürdürülebilir gelişme/kalkınma arasındaki iç içe, yan yana ve üst üste sistemik ilişkilerden hareketle, ekolojik ve sosyoekonomik iki doğal sermaye stoğunun, insan refahını tamamlayan ve artıran ekosistem hizmetlerinin sunduğu bir kurama dayanarak, ekolojik-sosyo-ekonomik sistemin ve epistemolojik yapının dinamikleri ve sürdürülebilirlik koşulları karşıllaştırılmaktadır.

Sistemin belirli bir durumunda dirençliliğin sürdürülebilir gelişme ve kalkınma için hem gerekli hem de yeterli olduğunun, dirençliliğinin yeterli, ancak gerekli olup olmadığının, dirençliliğinin gerekli, ancak yeterli olup olmadığının ve sistemin dirençliliğinin sürdürülebilir kalkınma için ne gerekli ne de yeterli olup olmadığının çözümlemelerinin yapılacağı bu çalışmada, ekolojik-sosyo-ekonomik sistemlerin ve epistemolojik yapının kentsel sürdürülebilirlik yönetimi için stratejiler ve politikalar tasarlanırken sistemin mevcut durumunun dirençliliğinden daha fazla kriterin dikkate alınması gerektiği sonucuna ulaşılmaktadır.

Anahtar Kelimeler: Dirençlilik, Kentsellik, Sürdürülebilir Gelişme, Kalkınma, Antroposen

\footnotetext{
${ }^{1}$ Prof. Dr., Şehir ve Bölge Planlama Bölümü, Süleyman Demirel Üniversitesi, Isparta, Türkiye.

2 Doktora Öğrencisi, Mimarlık, Planlama ve Tasarım Anabilim Dalı, Süleyman Demirel Üniversitesi, Isparta, Türkiye.

*ilgili yazar / Corresponding author: erkanp555@yahoo.com
} 


\title{
Urbanism, Sustainability and Resilience in the Anthropocene Era
}

\begin{abstract}
In a changing world, it is time to reconsider the concepts of the sustainability and the resilience in urban scale. Anthropocene truth, which creates a world characterized by sustained sustainability in political debates, extreme complexity, radical uncertainties and unprecedented change/ transformation, has gone far beyond the point of ignoring. In such a world, even if it is only the goal of sustainability and resilience. So, it seems necessary to confront the fact that it is not even possible to define these concepts.
\end{abstract}

Different spheres of profession, while two abstract and complex concepts with different interpretations and definitions are sufficiently complex when the concepts of resilience and sustainable development come together, an even more chaotic situation arises when the age of Anthropocene enters urbanism and dominance of human. The Anthropocene is not only an anthropogenic period of change, it is a concept that tells us to rethink about our world and the planet we live in, and has profound implications for development / transformation.

At the urban and regional level, resilience as a descriptive concept gives an idea of the dynamic characteristics and capacity of adaptation of an urban system, while sustainability is a normative concept, presenting the basic ideas of inter-generational and trans-generational justice. In this study, interdependent, intermittent and overlapping systemic relations between resilience, urbanism and sustainable development, the ecological and socioeconomic ecosystem services complement the ecological and socio-economic system and the epistemological structure and the dynamics of sustainability.

In this study, in a particular case where the resilience of the system is both necessary and sufficient for sustainable development and development, its resilience is sufficient, but necessary, its resilience is necessary, but sufficient, and the resilience of the system is neither necessary nor sufficient for sustainable development. When designing strategies and policies for urban sustainability management of ecological-socio-economic systems and epistemological structure, it is concluded that more criteria should be taken into consideration then the resilience of the existing system.

Keywords: Resilience, Urbanism, Sustainable Development, Anthropocene

\section{GíRiş}

Birleşmiş Milletler Sürdürülebilir Kalkınma Hedeflerine (Sustainable Development Goals SDG's) ulaşmak için son tarih olan 2030 yılına kadar, kentleşmenin küresel nüfusun $\% 60$ 'ını geçmesi bekleniyor (UN, 2014). Birleşmiş Milletler tarafından yapılan tahminler, şu anda 863 milyondan fazla gayrı resmi yerleşimci de dâhil olmak üzere 4 milyardan fazla küresel kentli insan olduğunu ve bunun her 10 günde bir yaklaşık 1 milyon arttığını gösteriyor (Acuto et al., 2018). Kentsel bölgeler küresel GSYIH'nın \%75'inden fazlasına katkıda bulunuyor, ancak aynı zamanda küresel enerji talebinden ve karbon emisyonlarından da sorumlu. Kentlerin bugünkü ve gelecekteki bölgesel ve küresel önemi (Bai et al., 2018; Seto et al., 2012), kent nüfusunun küresel nüfusun \%55'i olması ile tam bir çelişkidir.

Bu nedenle, şu anki yüzyıl, kentlerin zorlukları anlamak, farklı öncelikleri ve hedefleri uyumlaştırmak ve daha iyi kentsel geleceklerin politika ve yönetişimini stratejik olarak planlamak için temelde yeni bir bütünsel bakış açısına intiyaç duyacağı "kentsel yüzyıl" 
olarak etiketlenmelidir. Kentlerin oldukça dirençli karmaşık sistemler olduğu kanıtlanmıştır: Birçok kent binlerce yıldır var olmuştur ve doğal ve insan kaynaklı felaketler karşısında daha güçlü ve bazı durumlarda daha esnek olmaları için ısrar etmiştir.

Kentleşme ve kentsel alanlar, toplum ve çevre arasındaki ilişkiyi derinden değiştiren, hem kentsel hem de dünya sisteminin sürdürülebilirliğini ve dirençliliğini karmaşık şekillerde ve endişe verici oranlarda etkileyen dünya çapında fenomenlerdir. Son yıllarda, sürdürülebilirlik, dirençlilik ve dönüşüm, kentleşme ve çevresel değişimin yol açtığı bir dizi zorlu meseleyi anlamaya ve yanıtlamaya yönelik temel kavramlar haline gelmiş durumda.

Yine de, bu kavramların tanımları ve yaklaşımları sürekli değişiyor ve tartışmalı olsa da, ortak temalar etrafında dönüyorlar ve hatta büyük ve zorlayıcı sorular soruyorlar: Artan dünya nüfusumuzla birlikte, azalan ekosistemleri ile ısınmakta olan bir gezegende nasıl yaşarız (veya hayatta kalabiliriz)? Ne tür kentsel (veya kırsal) yaşamlar istiyoruz ve bu yaşamları gelecekte nasıl bir dünya sağlayabilir? Dahası, sürdürülebilirliği ve dirençliliği pratiğe dönüştürmek için kritik öneme sahip, hayatta kalmamızı ya da yaşama ve gelişme yollarımızı dönüştürmemizi sağlayacak hangi kapasitelere ihtiyacımız var?

Artık değişen bir dünyada, kentsel ölçekli sürdürülebilirlik ve dirençlilik kavramlarını toplu olarak yeniden gözden geçirme zamanı geldi de geçiyor bile. Politik tartışmalarda sürdürülebilirliğin sürdürülmesi, aşırı karmaşıklık, radikal belirsizlikler ve benzeri görülmemiş bir değişim/dönüşüm ile karakterize edilen bir dünya yaratan Antroposen gerçeği görmezden gelme noktasının çok ötesine geçmiş durumda. Böyle bir dünyada, "sürdürülebilirlik ve dirençlilik" kavramlarının sadece birer hedef olarak alındığı, hatta tanımlanmalarının bile mümkün olmadığı gerçeği ile yüzleşmemiz artık şart görünüyor.

Sosyal, politik ve finansal belirsizlikler karşısında kalkınma zorluklarının üstesinden gelmek ve artan küresel çevresel riskler ile etkileşime girmek, sosyal, ekonomik ve ekolojik şoklar, ister istemez kalkınmaya yeni bir bakış gerektiriyor. Bugünün çalkantılı ve yeni küresel koşullar altında kentselliği gözeten, dirençli, uygulanabilir ve sürdürülebilir kalkınma stratejilerine intiyaç duyulduğu açıktır.

Farklı uzmanlık kürelerinde, farklı yorum ve tanımlara sahip iki soyut ve karmaşık kavram olan dirençlilik ve sürdürülebilir gelişme/kalkınma kavramları bir araya geldiğinde yeterince karmaşıkken, kapsama alanına kentsellik ve insanın baskınlığı/egemenliği anlamında Antroposen Çağı girdiğinde daha da kaotik bir durum ortaya çıkmaktadır. Antroposen, yalnızca antropojenik bir değişim dönemi değildir, dünyamız ve yaşadığımız gezegen hakkında yeniden düşünmemiz gerektiğini anlatan bir kavramdır ve gelişim/dönüşüm için derin etkileri vardır.

Kentsel ve bölgesel ölçekte, dirençlilik tanımlayıcı bir kavram olarak bir kentsel sistemin dinamik özellikleri ve uyum sağlama kapasitesi hakkında fikir verirken, sürdürülebilirlik normatif bir kavram olarak, nesiller arası ve nesiller-ötesi (trans-generational) adaletin temel fikirlerini ortaya koyar. Bu çalışmada dirençlilik, kentsellik ve sürdürülebilir gelişme/kalkınma arasındaki iç içe, yan yana ve üst üste sistemik ilişkilerden hareketle, ekolojik ve sosyoekonomik iki doğal sermaye stoğunun, insan refahını tamamlayan ve artıran ekosistem hizmetlerinin sunduğu bir kurama dayanarak, ekolojik-sosyo-ekonomik sistemin ve epistemolojik yapının dinamikleri ve sürdürülebilirlik koşulları karşıllaştırılmaktadır.

Sistemin belirli bir durumunda dirençliliğin sürdürülebilir gelişme ve kalkınma için hem gerekli hem de yeterli olduğunun, dirençliliğinin yeterli, ancak gerekli olup olmadığının, dirençliliğinin gerekli, ancak yeterli olup olmadığının ve sistemin dirençliliğinin sürdürülebilir kalkınma için ne gerekli ne de yeterli olup olmadığının çözümlemelerinin yapılacağı bu çalışmada, 
ekolojik-sosyo-ekonomik sistemlerin ve epistemolojik yapının kentsel sürdürülebilirlik yönetimi için stratejiler ve politikalar tasarlanırken sistemin mevcut durumunun dirençliliğinden daha fazla kriterin dikkate alınması gerektiği sonucuna ulaşılmaktadır.

\section{NEDEN ANTROPOSEN?}

Dünya... Güneş Sistemi'nde Güneş'e en yakın olan üçüncü gezegen. Şu an için üzerinde yaşam olduğu bilinen tek gezegen, yuvamız. Yaşı: 4,543E9 yıl, Yarıçapı: $6.371 \mathrm{~km}$, Yüzölçümü: 510.100 .000 km², Ağırlığı: 5,972E21 t ve Nüfusu: 7.715 Milyar kişi.

4,5 Milyar yaşındaki dünyamızın son on bin yılını kapsayan ve insan uygarlığının geliştiği jeolojik devrin adı olan 'Holosen' i bitirecek yeni çağın resmi adının konulması artık an meselesi. Holosen, jeolojik zamanın son halkası. İnsanın ortaya çıkışından günümüzü de içine alarak bir sonraki buzul çağına kadarki süreyi kapsayan zaman dilimi; kısaca YENIÇAĞ.

Bazı yazarlar Holosen'in bittiğini ve artık yeni bir döneme girdiğimizi savunuyor; Dünya atmosferinin, litosfer ve biyosferin insan güçleri tarafından şekillendirildiği bir jeolojik dönem: ANTROPOSEN (Anthropocene) ÇAĞI...

80'lerden bu yana insanın doğa üzerinde güçlü bir dönüştürücü tahakküme sahip olduğu çağı ifade etmek için kullanılan bir kavram. İçüdüsel yapısı olmadığı için insan kendine ekolojik yaşam alanları üretme gereksinimi duymadığı gibi, ayak izinin ve elinin uzandığı her yeri ve her şeyi de kendi yaşam biçimine uygunlaştırarak ve uyumlaştırarak, Dünya dediği gezegeni uzun bir süredir değiştiriyor ve dönüştürüyor.

Antroposen insanın içinde olduğumuz çağda yaptığı müdahalelerin ve yarattığı etkinin boyutunu özellikle imlemek için kullanılan bir kavram (Crutzen and Stoermer, 2000). Doğal ve sosyal bilimler arasında ciddi tartışmalar yaratmış yeni bir kavram olarak da tartışılır (Castree, 2014; Johnson et al., 2014).

$\mathrm{Bu}$ yüzden çoğunlukla kapitalizmin hatta neo-liberalizmin girdileri ve çıktıları ile sıkça ilişkilendirilir. Geniş bir alana yayılarak, bilimin temelini ve kavramsal ve estetik bir kelime dağarcığını oluşturmayı sağlamış ve dünyanın geleceğini şekillendirmeye kadar ulaşmıştır.

Antroposen kavramı, özde, insan (antropos/anthropos) ve faaliyetlerinin dünyaya etkilerinin "büyük bir ivme" geçirdiğini anlatır. Antroposen, küresel çevresel değişimi anlamak için bir sosyo-kültürel-mekansal bir bütünleşik çerçeve sunar ve çevre siyaseti için de bir platform oluşturur. Böylece, epistemolojik, politik ve normatif kaygıları bir araya getiren anlaşılır ve zorlayıcı anahtar bir anlatı sunar.

Bir taraftan da Antroposen fikri, süper bilişim ve iklim değişikliği modellemesinin temelini de oluşturmaktadır. Son yıllarda, iklim krizine bir cevap olarak kazandırılan bir kavram olan dirençlilik fikrini de şekillendirmiştir.

\section{META-ENDÜSTRIYYEL DÖNEM VE KENTSEL DİRENÇLILIIK}

1972'deki Roma kulübünün ünlü Meadows Raporu «Büyümenin Sınırları» nın kehanetleri neredeyse gerçekleşti: İklim değişikliği, biyolojik çeşitlilik kaybı, deniz seviyesinin yükselmesi, mülteci krizleri, yeni çatışmalar vs.

Depremlerden sele, hızlı göçlerden sınırsız kentleşmeye kadar bütün kentler, hem doğal hem de insan yapımı bir dizi yeni ve güçlendirilmiş şok ve stresle karşı karşıya. Bu olgusal 
artış, kentlilerin ve insanın farklı tehlikelere maruz kalmasını ve kırılganlığını arttırmakta, felaketleri tetiklemekte ya da daha da kötüleştirebilmektedir. İklim değişikliğinin etkileri daha şiddetli ve sık hale geldiğinden, kentsel alanlarımıza daha fazla stres uygulanmaktadır.

Kentsel dirençlilik, son zamanlarda popülerlik ve kabul gören, mevcut farklı riskleri içeren bir kavram olarak yıkıcı zorluklara karşı koyabilme ve bir geri tepme kapasitesidir. Esnek kentler, taşkınlar, depremler, kasırgalar ve terör saldırıları sonucundaki riskleri azaltmak için bir planlama ve eylemdir. Günümüzde, esnek, duyarlı, uyarlanabilir ve birbirine bağlı, küresel kademede hızlı değişen koşullarla başa çıkmak en zor durum olarak karşımızda.

$\mathrm{Bu}$ kadar olumsuzluk karşısında, yeni bir bilincin oluşmasını (maalesef) hiç bir şey yap(a)madan izliyoruz; merkeziyetçilik ve ademi merkeziyetçilik, bilim ve ilim, endüstri ve ekoloji, teknoloji ve işçilik, bereket ve ekonomi, yerellik ve küresellik, iş ve oyun, eğitim ve yaşam ifadesi, çeşitlilik ve birlik, yalnızlık ve samimiyet...

Bu değişimleri azaltmak ve insanlar üzerindeki olumsuz etkilerini azaltmak için kentlerin ve kent insanının yeteneklerini güçlendirerek, kentlerimizde dirençliliği arttırmak bir zorunluluk olarak görünüyor.

Antroposen'de sözde yeni normal - ya da yeni anormal olarak kavramlaştırmak belki de daha doğru - yaşam; belirsizlik, tahmin edilemezlik, gerçek kaos ve acımasız değişim ile karakterize edilmekte. Bu gezegensel sıkıntı, küresel ısınma, iklim değişikliği, değişken hava-toprak-su, asitleşen okyanuslar, hastalık salgınları, türlerin tehlikeye girmesi ve neslinin tükenmesi, toksinlerin biyolojik birikimi ve üssel olarak artan insan nüfusunun ezici fiziksel etkisiyle kendisini her geçen gün daha da hissettirmektedir.

Her sayılan faktör kendi başına olduğunda bile tek başına endişe vericiyken, Antroposen kavramı, tüm bu faktörleri ve diğerlerini bir araya getirir. Bu, Dünya'yı geri dönüşüm ve bildirim döngüleri ve henüz tahmin edemediğimiz devrilme noktaları olan tek bir yankı sistemi olarak anlayabilmemizin tek yoludur.

Bu noktada, kent, Antroposenin bir başlatanı ve sonucu olarak rol oynar; son yüzyılın işletim sistemini yeniden tasarlayarak pastamızı da yiyip, sanayileşmeyi iki katına çıkarmamızı sağlayabilen bir mekânsal ve altyapı biçimidir (Townsend, 2013). Kentsel ölçekte bunun net analojileri vardır; burada analitik nesne, kentler büyüdükçe ve insanlık tarihinde daha önce hiç görülmemiş seviyelere çıktıkça, daha önce benzeri görülmemiş bir şekilde hızla da dönüştürülür (Davis, 2006; Brenner, 2014). Bilinen herhangi bir temelin yokluğu ile 'yeni ekolojileri' benimseme ihtiyacı ya da sürekli hareket eden denge noktaları hem bilimsel hem de politik kaygılar yaratır. Bu kaygılar, 'büyük veri (big data)' tarafından üretilen kentsel ve çevresel "okunaklılık" formunda görünüşte sakinleşmekte ya da kesilmektedir.

Antroposenle ilişkisi bağlamında kentsel dirençlilik altında yatan ontoloji, dâhil olduğu kentsel gelecek ve kentsel yönetişim ile eklemlendiği siyasetin ideolojilerine kadar derinleşir. Önemli bir biçimde, dirençlilik "riski merkezleştirir ve normalleştirir" ve kaçınılmaz olan felakete karşı "uyum sağlama yeteneğini önceliklendirir". Bu açıdan, dirençlilik altında yatan ontoloji "aslında savunmasızdır" ve güvenlik açığını azaltmak, dayanma kapasitesini geliştirmek için dirençliliğin sosyo-ekolojik olarak ve direnişin "siyasi olarak" aşağılanması anlamına da gelmektedir (Evans and Reid, 2013: 84).

Kentsel dirençlilik, herhangi bir yerleşim sisteminin, sakinleriyle birlikte, tüm şok ve streslerle sürekliliğini sürdürürken, pozitif olarak sürdürülebilirliğe adaptasyonu ölçülebilir bir kabiliyetidir.

Dirençli bir kent, insanlarının yaşamlarını korumak ve iyileştirmek, kalkınma kazançlarını güvence altına almak, yatırım ortamını geliştirmek, doğal ve insani, ani ve yavaş başlayan, 
beklenen ve beklenmedik tehlikelere hazırlıklı olmak ve bunlara müdahale etmek için değerlendirir, planlar, davranır ve pozitif değişime neden olur.

Kalkınmanın ve kentleşmenin çevresel sınırları uluslararası, ulusal ve yerel olarak giderek daha fazla kabul edilmekle birlikte, kentsel sürdürülebilirliğe ve dirençliliğe nasıl geçileceği konusunda çok az bir uzlaşı vardır. Bazıları için, kentsel sürdürülebilirlik ve dirençlilik, daha fazla bilgi, yenilik ve teknik uzmanlık ile ele alınabilecek teknik problemlerdir. Diğerleri bu zorlukları altta yatan kentsel gelişim itici güçlerini ve çevresel değişimin nedenlerini araştırmak ve ele almak için fırsatlar olarak görmektedir (O’Brien, 2012; Pelling, 2010).

Bu bağlamda, bilimsel veya uzman bilgisinden türetilmiş eylemlerden kaynaklanmak yerine, kentsel sürdürülebilirlik ve dirençlilik, sosyal ve ekolojik sistemler arasındaki etkileşimler biliminin gerekli ancak yeterli olamayacağını gösterir. Bu nedenle, geleceğe yönelik tüm hedefler, değişime yönelik sosyal, ekonomik, teknolojik ve ekolojik kısıtlamalar ve farklı hareket tarzlarının etkileri hakkında belli bir anlayışla ortak bir potada bir araya getirilmelidir (Robinson and Cole, 2015).

\section{SONUÇ YERINE}

Yirmi birinci yüzyılın zorlukları - kaynak kısıtlamaları, finansal istikrarsızlık, ülkeler içindeki ve arasındaki eşitsizlikler, çevresel bozulma - her zamanki rutinin devam edemeyeceği konusunda açık bir işarettir. Yeni bir insani deneyim aşamasına geçiliyor ve bildiklerimizden niteliksel ve niceliksel olarak farklı olacak yeni bir dünyaya giriyoruz. Dünyanın dört bir yanındaki kentler, değişen demografik ve çevresel baskılarla bağlantılı bir dizi birbirine bağlı zorluklar ve fırsatlarla karşı karşıya. Kentlerin ve sakinlerinin hayatta kalması ve gelişmesi için, iyi koordine edilmeleri ve farklı baskılara etkili bir şekilde yanıt vermeleri gerekiyor.

Kentleşme süreçleri, Antroposen'de değişimi tetikleyerek, ölçek, kapsam ve karmaşıklıkta benzeri görülmemiş çevresel ve sosyal zorlukları ortaya koymaktadır. İklim değişikliği, yerel kurumlara uyum sağlama ve dirençlilik konusunda baskı uygulayarak ilave belirsizlikler getirmekte, kentlerin kilit fonksiyonları etkin bir şekilde ayarlaması ve sürdürmesi için gereken aktörleri ve kaynakları bir kenara atar biçimde "kentsel dirençlilik" kavramına yönelmektedir.

Antroposen insan kaynaklı değişimin ölçeği ve temposunun - biyolojik çeşitlilik kaybının, atmosfer ve okyanus kimyasındaki değişimlerin, kentleşmenin, küreselleşmenin - bağımsız bir ölçüsüdür ve bunları dünya tarihinin derin bağlamına yerleştirir. Ortaya çıkan Antroposen dünyası, azalan bir buz örtüsü, daha fazla deniz ve daha az toprak, değişen yağış düzenleri, kuvvetle modifiye edilmiş yoksul bir biyosfer ve insanın hakim olduğu manzaralarla daha sıcak bir dünya.

Demokrasi, sürdürülebilirlik, sürdürülebilir kalkınma, dirençlilik ve uyum kapasitesi gibi kavramlar etrafında yeni ve yaşanabilir bir toplum kurmaya çalışmış olsak da; tüm bu terimler de normalleştirildikleri, her zamanki gibi iş yaptıkları Antroposene dahil edildikleri ve yerleştirilmeye çalıştıkları için bu kuvvetler tarafından -artık- bozulmuştur.

Faaliyetlerimizin "Dünya Sistemi"ni nasıl etkilediği hakkında geniş bir bilgiye sahip olan ilk nesiliz, bu nedenle de gezegenle olan ilişkimizi değiştirme gücüne ve sorumluluğuna sahip olan da ilk nesiliz. Antroposeni doğru yönetemezsek, insanlık için belirsiz bir geleceğe doğru, Dünya Sistemi'nin yeni ama çok farklı bir haliyle, tek yönlü bir yolculuğa çıkma tehdidi ile yüz yüze kalacağız demektir. 
Antroposen içindeki tüm bu olumsuz eğilimlere karşı koymak için, popüler politika ve kültür içinde farklı bir geleceğin yeni vizyonlarına, kültürel bir evrime ve hayatta kalmaya açıkça ihtiyacımız var. Antroposen'in birbiriyle ilişkili sistematiği bir problem değil, çok boyutlu bir çıkmaz sunarken, insan nesli olarak bizler bu çıkmazları çözmüyoruz; bunun yerine, sadece onlar arasında gezinip duruyoruz.

İnsan etkisinin gittikçe yaygınlaştığı ve kentlerin sosyal-ekolojik-teknolojik sistem yapıları ve süreçlerinin merkezi olduğu yerlerde, bir taraftan değişimi ve belirsizliği belirleyen ve tetikleyen diğer taraftan da belirsizliği gideren bir sistem çerçevesine intiyacımız var. İçinde olduğumuz kentsel yüzyılda değişim ihtiyacını ve temel dönüştürücü çözümlerin daha iyi desteklenmesi sürdürülebilirlik, dirençlilik ve dönüşümlerin yeni bir kavramsallaştırmasına doğru atılmış ilk adımdır.

Hâlâ eksik bilgiye sahip olduğumuz, çözmemiz gereken çok sayıda zorlayıcı soru olması da bir başka gerçeklik:

- Kentleşme, iç içe geçmiş insan ve gezegen sisteminin çeşitlenmesi veya basitleşmesi ile sonuçlanır mı?

- Kentlerin artan bağlantılığı, insan ilişkilerini yönetmede ve biyosferi şekillendirmede kendi başına bir güç haline gelir mi?

- Kentsel dirençlillikte Antroposen'in rolü nedir, aşırı bağlanabilirlik yeni güvenlik açıklarına ya da risklere neden olur mu?

- Kentlerin, küresel kalkınmayı ve sürdürülebilirliği daha çekici yörüngelere doğru kaydırmasında, Antroposen'in dengeleyici ve dirençliliği güçlendirici bir yapı haline gelmesi mümkün olur mu?

Sonuçta, kentsel sürdürülebilirlik, kentsel esneklik ve kentsel dönüşümler, kentsel alanların, kentsel gelişme, kentsel karar alma ve kentsel yönetişimin, Antroposenin yaygın insan etkinliği olarak biyolojik alanımızı ve Dünya Sistemi dinamiklerini şekillendirmedeki önemli rolü ile ilgilidir.

Çalıların etrafından daha fazla da dolaşmayalım, gerçek şu ki, biz insanlar, gezegene bir bela olmanın eşiğindeyiz. Acımasız "yaratıcı yıkım" ve karbon temelli kapitalizmin "hafriyatçılık (extractivism)" koşulları altında, "insan" diğer tüm türlere ve ekosisteme karşı maalesef bir belaya dönüşüyor. Ekosistemin sınırlarını epeyce zorladığımız için de, batan gemiden ilk kaçanlar olma şansımız da yok gibi. Gidecek neresi kaldı ki?

Çünkü; başka bir Dünya yok! 


\section{KAYNAKLAR}

Acuto, M., Parnell, S. \& Seto, K. C. (2018). Building a Global Urban Science. Nat. Sustain. 1, 2-4.

Bai, X., Dawson, RJ., Ürge-Vorsatz, D., Delgado, GC., Salisu Barau, A., Dhakal, S., Dodman, D., Leonardsen, L., Masson-Delmotte, V., Roberts, DC., Schultz, S. (2018). Six Research Priorities for Cities and Climate Change. Nature 555, 23-25.

Brenner, N. (2014). Implosions/Explosions. Berlin: Jovis.

Castree, N. (2014). Geography and the Anthropocene II: Current Contributions. Geography Compass, 8(7), 450-463.

Crutzen, PJ., Stoermer, EF. (2000). The Anthropocene. Glob. Chang. Newsl. 41:17-18.

Davis, M. (2006) Planet of Slums. New York: Verso.

Evans, B., Reid, J. (2013). Dangerously Exposed: The Life and Death of the Resilient Subject. Resilience 1(2): 83-98.

Johnson, E., Morehouse, H., Dalby, S., Lehman, J., Nelson, S., Rowan, R., Wakefield, S., Yusoff, K. (2014). After the Anthropocene. Progress in Human Geography38(3):439-456.

O'Brien, K. (2012). Global Environmental Change II From Adaptation to Deliberate Transformation. Prog. Hum. Geogr, 36, 667-676.

Pelling, M. (2010). Adaptation to Climate Change: From Resilience to Transformation. Routledge: Abingdon-on-Thames, UK.

Robinson, J., Cole, R.J. (2015). Theoretical Underpinnings of Regenerative Sustainability. Build. Res. Inf., 43, 133-143.

Seto, K. C., Reenberg, A., Boone, C. G., Fragkias, M., Haase, D., Langanke, T., Marcotullio, P., Munroe, D. K., Olah, B., Simon, D. (2012). Urban Land Teleconnections and Sustainability. Proc. Natl. Acad. Sci. USA 109, 7687-7692.

Townsend, A. (2013). Smart Cities: Big Data, Civic Hackers, and the Quest for a New Utopia. New York: WW Norton \& Co.

UN, (2014). World Urbanization Prospects: The 2014 Revision (United Nations Department of Economic and Social Affairs). 